\title{
Pengaruh Pemberian Reward dan Disiplin Kerja Terhadap Prestasi Kerja yang Berdampak pada Kinerja Karyawan pada PT Surya Pratama Gemilang di Bekasi
}

\author{
${ }^{1}$ Suwanto, ${ }^{2}$ Denok Sunarsi, ${ }^{3}$ Heri Erlangga, ${ }^{4}$ Nurjaya, ${ }^{5}$ Rofiq Noorman Haryadi \\ ${ }^{1.2}$ Universitas Pamulang, Tangerang Selatan, Banten, Indonesia \\ ${ }^{3}$ Universitas Pasundan, Bandung, Jawa Barat, Indonesia \\ ${ }^{4}$ Universitas Suryakancana, Cianjur, Jawa Barat, Indonesia \\ ${ }^{5}$ STEBIS Bina Mandiri, Cileungsi Kidul, Kec. Cileungsi, Bogor, Jawa Barat \\ Email:11dosen01813@unpam.ac.id
}

(Diterima: Desember 2021; Direvisi: Desember 2021; Dipublikasikan: Januari 2022)

\begin{abstract}
ABSTRAK
Penelitian ini bertujuan untuk mengetahui pengaruh pemberian reward dan disiplin kerja terhadap prestasi kerja yang berdampak pada kinerja karyawan pada PT. Surya Pratama Gemilang di Bekasi. Metode yang digunakan adalah explanatory research dengan sampel sebanyak 96 responden. Teknik analisis menggunakan analisis statistik dengan pengujian regresi, korelasi, determinasi dan uji hipotesis. Hasil penelitian ini Pemberian reward berpengaruh signifikan terhadap prestasi kerja sebesar 38,3\%, uji hipotesis diperoleh signifikansi $0,000<$ 0,05. Disiplin kerja berpengaruh signifikan terhadap prestasi kerja sebesar 40,5\%, uji hipotesis diperoleh signifikansi $0,000<0,05$. Pemberian reward dan disiplin kerja secara simultan berpengaruh signifikan terhadap prestasi kerja sebesar 50,4\%, uji hipotesis diperoleh signifikansi $0,000<0,05$.Prestasi kerja berpengaruh signifikan terhadap kinerja karyawan sebesar 38,4\%, uji hipotesis diperoleh signifikansi $0,000<0,05$.
\end{abstract}

\section{Kata Kunci: Pemberian Reward, Disiplin Kerja, Prestasi Kerja, Kinerja} Karyawan 


\section{PENDAHULUAN}

Manajemen sumber daya manusia (MSDM) pada era globalisasi dan persaingan bebas saat ini perlu mendapatkan perhatian yang lebih besar, karena sumber daya manusia yang mengelola dan mengatur sumber daya lainnya baik pada tingkat makro (nasional) maupun pada tingkat mikro yaitu pada tingkat organisasi dengan segala jenis bentuk maupun kegiatannya (Bernadin dan Russel, 2010).

Sumber Daya Manusia (SDM) merupakan salah satu unsur penting. Peran serta fungsinya tidak bisadigantikan oleh sumber daya yang lain dan dimana kebutuhannya harus di penuhi dengan baik. Walaupun didukung dengan sarana dan prasarana yang memadai. SDM yang berkualitas merupakan sumber daya manusia yang memiliki keahlian, profesionalitas, produktif dan mampu secara mandiri bersaing dengan sehat di dunia kerja dan diharuskan mempunyai wawasan terhadap lingkungan sekitar (Hamali, 2016). Hal ini tentunya tidak luput dari berbagai faktor pendukung dalam meningkatkan produktivitas karyawan diantaranya pemberian imbalan yang setimpal dengan kinerja karyawan, di luar gaji yang di terima oleh karyawan.

PT. Surya Pratama Gemilang adalah perusahaan yang bergerak dibidang pengadaan produk contraktor, general trade, supplier, Export - Import khususnya Carton Box. Berdiri sejak tahun 1992, Perusaan ini mampu mengembangkan usahanya dibidang "Manufacturing \& Trading" yang memiliki komitmen untuk mendukung semua kegiatan perusahaan dalam menghasilkan product yang berkualitas tinggi. Kegiatan usaha ini merupakan kegiatan produksi dan pengadaan barang khususnya Plastic Corugated Box, Carton Box, Pallet, Plastic \& Paper Partition, Packaging Printing dan Dampla. Selain mengedepankan Quality, Cost, Delivery dan Management, perusahaan kami mempunyai dedikasi yang tinggi dan menjunjung tinggi profesionalisme kerja. Seiring dengan perkembangan bisnis packaging di Indonesia di mana kebutuhan akan carton box packaging terus mengalami peningkatan, oleh karenanya kami juga siap melayani permintaan dari segala lapisan pelanggan, mulai dari yang kecil sampai yang besar.

Dalam pengelolaan sumber daya yang dimiliki perusahaan terbatas sifatnya, maka perusahaan dituntut untuk mampu memberdayakan dan mengoptimalkan guna mencapai tujuan dan mempertahankan kelangsungan hidupnya. Sumber daya manusia (SDM) merupakan salah satu keunggulan bersaing perusahaan dalam efisiensi, efektivitas dan fleksibilitas perusahaan dalam mencapai tujuannya. Tuntutan tugas yang ada pada suatu perusahaan adalah salah satu penyebab timbulnya disiplin kerja pada karyawan. Pemberian reward tidak hanya untuk mempertahankan karyawan, tetapi juga untuk memotivasi karyawan untuk bekerja lebih baik lagi. Dengan memberikan reward kepada karyawan dapat mendorong karyawan untuk memiliki perilaku dan sikap yang lebih positif dalam bekerja yang dapat meningkatkan produktivitas. 
Pemberian insentif merupakan salah satu hal pokok yang harus diperhatikan oleh perusahaan. Disiplin tidaknya karyawan bisa juga disebabkan oleh besar kecilnya insentif yang diterima. Apabila karyawan tidak mendapatkan insentif yang sesuai dengan besarnya pengorbanan dalam bekerja, maka karyawan tersebut cenderung malas bekerja dan pada akhirnya mempengaruhi prestasi kerja-nya.

Menurut Hasibuan (2010) reward adalah daya perangsang yang diberikan kepada karyawan tertentu berdasarkan prestasi kerjanya agar karyawan terdorong meningkatkan produktifitas kerjanya. Dengan adanya pemberian insentif yang tepat serta cara kerja yang baik sehingga ke depannya, proses kerja organisasi dapat berjalan sesuai tujuan organisasi.

Faktor lain yang mampu meingkatkan prestasi kerja adalah adanya penerapan disiplin atas peraturan yang dibuat di perusahaan mampu dijalankan dengan baik. Disiplin kerja merupakan hal yang harus ditanamkan dalam diri setiap karyawan, karena hal ini akan menyangkut tanggungjawab moral karyawan itu pada tugasnya (Trang, Lengkong, Dotulong, 2015).

Penilaian prestasi kerja karyawan cukup penting bagi karyawan maupun perusahaan karena dari penilaian kerja menjadi pusat perencanaan karir bagi karyawan sekaligus mendapatkan promosi. Bagi perusahaan, penilaian prestasi kerja karyawan bisa menjadi motivasi untuk karyawan agar bekerja lebih baik lagi. Penilaian prestasi kerja dapat membantu seorang pimpinan dalam mengantisipasi dan mencegah ketidakpuasan karyawan. Perubahan sikap karyawan merupakan tandatanda adanya perubahan dalam kepuasan kerja karyawan. Prestasi kerja karyawan yang tinggi dari setiap karyawan merupakan hal yang sangat diinginkan untuk perusahaan. Semakin banyak karyawan yang berprestasi, maka kinerja atau produktifitas organisasi secara keseluruhan akan meningkat dan perusahaan dapat bertahan dalam persaingan bisnisnya.

Kinerja sangat penting bagi organisasi karena (1) kinerja yang tinggi tentu dapat mengurangi angka absensi atau tidak bekerja karena malas, (2) dengan kinerja yang tinggi dari buruh dan karyawan maka pekerjaan yang diberikan atau ditugaskan kepadanya akan dapat diselesaikan dengan waktu yang lebih singkat atau lebih efisien.

Hasil dari penilaian kinerja nantinya dapat digunakan sebagai informasi dalam menentukan kompensasi secara layak sehingga karyawan dapat memotivasi karyawan. Hasil dari penilaian kinerja tersebut tentunya dapat digunakan untuk menentukan program pelatihan dan pengembangan yang lebih efektif.

Penilaian kinerja dibutuhkan untuk mengetahui tingkat keberhasilan kinerja setiap karyawan. Penilaian kinerja digunakan untuk menilai keberhasilan atau kegagalan pelaksanaan kegiatan atau kebijaksanaan sesuai dengan tujuan yang telah ditetapkan dalam rangka mewujudkan misi dan visi perusahaan.

Berdasarkan latar belakang di atas penulis tertarik untuk meneliti tentang "Pengaruh Pemberian 
Reward Dan Disiplin Kerja Terhadap Prestasi Karyawan Yang Berdampak Pada Kinerja Karyawan Pada PT. Surya Pratama Gemilang di Bekasi”.

\section{TINJAUAN PUSTAKA}

\section{Pemberian Reward}

Reward merupakan suatu bentuk teori penguatan positif yang bersumber dari teori behavioristik. Menurut Ngalim Purwanto (2019:182) menjelaskan bahwa Reward adalah alat untuk mendidik anak-anak supaya anak dapat merasa senang karena perbuatan atau pekerjaannya mendapat penghargaan

\section{Disiplin Kerja}

Menurut Rivai (2019:44) berpendapat bahwa "Disiplin Kerja "Suatu alat yang digunakan para manajer untuk berkomunikasi dengan karyawan agar mereka bersedia untuk mengubah suatu perilaku serta sebagai suatu upaya untuk meningkatkan kesadaran dan kesediaan seseorang mentaati semua peraturan perusahaan dan norma-norma sosial yang berlaku"

\section{Prestasi Kerja}

Menurut Rivai (2019:44) berpendapat bahwa "Disiplin Kerja "Suatu alat yang digunakan para manajer untuk berkomunikasi dengan karyawan agar mereka bersedia untuk mengubah suatu perilaku serta sebagai suatu upaya untuk meningkatkan kesadaran dan kesediaan seseorang mentaati semua peraturan perusahaan dan norma-norma sosial yang berlaku"

\section{Kinerja Karyawan}

Menurut Mangkunegara (2016:75) pengertian kinerja adalah hasil kerja secara kualitas dan kuantitas yang dicapai oleh seorang pegawai dalam melaksanakan tugasnya sesuai dengan tanggung jawab yang diberikan kepadanya. Adapun indikator yang digunakan sebagai berikut: Kualitas kerja, Kuntitas kerja, Pelaksanaan Tugas, Tanggung Jawab

\section{Model Penelitian}

Menurut pendapat Sugiyono (2018) "Model penelitian merupakan sintesa yang mencerminkan keterkaitan antara variabel yang diteliti dan merupakan tuntunan untuk memecahkan masalah penelitian serta merumuskan hipotesis yang berbentuk bagan alur yang dilengkapi penjelasan kualitatif". Dalam penelitian ini model penelitian yang dibuat sebagai berikut:

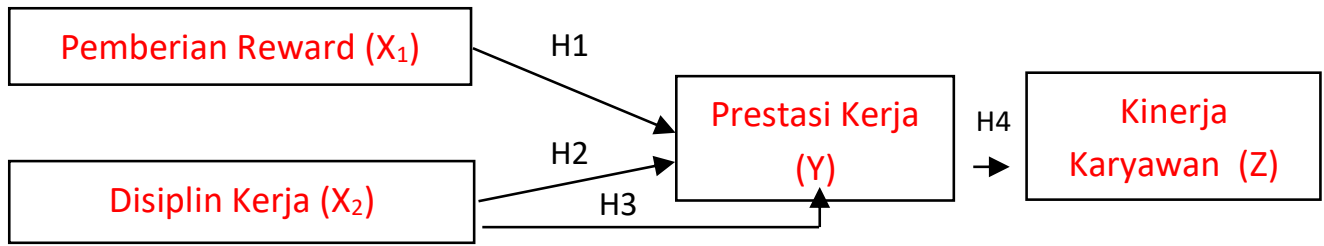

\section{Hipotesis Penelitian}

Menurut Sugiyono (2018) "Hipotesis merupakan jawaban sementara terhadap masalahmasalah, karena sifatnya
Gambar 1. Paradigma Model Penelitian

sementara maka perlu dibuktikan kebenarannya melalui data empirik yang terkumpul". Adapun rumusan hipotesis yang diajukan sebagai berikut: 
H1 : Terdapat pengaruh yang signifikan Pemberian reward terhadap prestasi kerja pada PT. Surya Pratama Gemilang di Bekasi.

H2 : Terdapat pengaruh yang signifikan disiplin kerja terhadap prestasi kerja pada PT. Surya Pratama Gemilang di Bekasi.

H3 : Terdapat pengaruh yang signifikan Pemberian reward dan disiplin kerja secara simultan terhadap prestasi kerja pada PT. Surya Pratama Gemilang di Bekasi.

H4 : Terdapat pengaruh yang signifikan prestasi kerja terhadap kinerja karyawan pada PT. Surya Pratama Gemilang di Bekasi.

\section{METODE PENELITIAN}

\section{Populasi}

Populasi dalam penelitian ini berjumlah 96 responden PT. Surya Pratama Gemilang di Bekasi

\section{Sampel}

Teknik pengambilan sampling dalam penelitian ini adalah samplel jenuh, dimana semua anggota populasi dijasikan sebagai sampel. Dengan demikian sampel dalam penelitian ini berjumlah 96 responden.

\section{Jenis Penelitian}

Jenis penelitian yang dipakai adalah asosiatif, dimana tujuannya adalah untuk mengetahui mencari keterhubungan antara

\section{Teknik Analisis Data}

Dalam menganalisis data digunakan uji instrumen, uji asumsi klasik, regresi, koefisien determinasi dan uji hipotesis.

\section{a. Uji Instrumen}

Pada pengujian ini digunakan uji validitas dan uji reliabilitas.

1) Uji Validitas.

Uji validitas dimaksudkan untuk mengetahui ketepatan data tentang kesesuaian antara yang mau diukur dengan hasil pengukurannya. Untuk melakukan uji validitas dilihat nilai signifikansi 2 tailed dibandingkan dengan 0,05 dengan dengan ketentuan:

1) Jika nilai signifikansi 2 talied $<0,05$, maka instrumen valid,

2) Jika nilai signifikansi 2 talied > 0,05, maka instrumen tidak valid,

2) Uji Reliabilitas.

Uji reliabilitas merupakan serangkaian pengukuran atau serangkaian alat ukur yang memiliki konsistensi bila pengukuran yang dilakukan dengan alat ukur itu dilakukan secara berulang. Instrumen yang baik tidak akan bersifat tendensius mengarahkan responden untuk memilih jawaban tertentu. Adapun kriteria yang digunakan sebagai berikut:

(a)Jika Cronbach's Alpha > 0,600, maka instrumen reliabel.

(b)Jika Cronbach's Alpha < 0,600, maka instrumen tidak reliabel.

\section{b. Uji Asumsi Klasik}

Uji asumsi klasik dimaksudkan untuk 
mengetahui ketepatan sebuah data. Dalam penelitian ini uji asumsi klasik yang digunakan adalah meliputi: Uji Normalitas, Uji Multikolinearitas, $\quad$ Uji Autokorelasi, dan Uji Heterokedastisitas. Adapun hasilnya sebagai berikut:

1) Uji Normalitas

Uji normalitas digunakan untuk menguji apakah dalam sebuah model regresi, variabel dependen, variabel independen, atau keduanya mempunyai distribusi normal atau tidak. Uji normilitas menggunakan Kolmogorov-Smirnov test, dengan ketentuan:

(a)Jika nilai signifikansi < 0,05 , maka data tidak berdistribusi normal.

(b)Jika nilai signifikansi > 0,05, maka data berdistribusi normal.

2) Uji Multikolinieritas

ini bertujuan menguji apakah pada model regresi ditemukan adanya korelasi antar variabel independen. Dalam penelitian ini digunakan batas tolerance dan lawannya, variance inflation factor (VIF) dengan ketentuan:

(a) Jika nilai nilai tolerance lebih < 1 dan nilai Variance Inflation Factor (VIF) < dari 1, maka tidak terjadi multikolinieritas.

(b) Jika nilai nilai tolerance lebih $>1$ dan nilai Variance Inflation Factor (VIF) $>$ dari 1, maka terjadi multikolinieritas.

3) Uji Autokorelasi

Uji autokorelasi digunakan untuk mengetahui ada atau tidaknya penyimpangan asumsi klasik autokorelasi, yaitu adanya korelasi antar anggota sampel. Dalam penelitian ini digunakan Durbin Watson Test.

4) Uji Heterskedastisitas

Uji

Htereoskaedastisitas

bertujuan untuk mengetahui apakah dalam model regresi terjadi ketidaksamaan varian dari suatu residual pengamatan ke pengamatan lain. Cara menprediksi ada atau tidaknya heteroskedastisitas digunakan Glejser Test.

\section{c. Uji Statistik}

1) Regresi Linier

Analisis regresi liner merupakan suatu teknik statistika yang digunakan untuk mencari persamaan regresi yang bermanfaat untuk meramal nilai variabel dependen berdasarkan nilainilai variabel independen. Dalam penelitian ini digunakan regresi linier berganda.

2) Koefisien Korelasi

Pengujian koefisien korelasi dimaksudkan untuk mengetahui tingkat kekuatan hubungan antara variabel independen dengan variabel dependen baik secara parsial maupun simultan". 
3) Koefisien Determinasi

Analisis koefisien determinasi dimaksudkan untuk mengetahui besarnya pengaruh antara variabel independen terhadap variabel dependen baik secara parsial maupun simultan.

4) Uji Hipotesis

Pengujian hipotesis dimaksudkan untuk menentukan apakah suatu hipotesis sebaiknya diterima atau ditolak. Dalam penelitian ini digunakan uji $\mathrm{t}$ (Parsial) dan uji $\mathrm{F}$ (Simultan).

\section{HASIL PENELITIAN}

1. Hasil Uji Instrumen

a. Dari hasil pengujian diperoleh seluruh item kuesioner variabel Pemberian reward diperoleh nilai signifikansi 2 tailed sebesar $0,000<0,05$, dengan demikian instrumen valid.

b. Dari hasil pengujian diperoleh seluruh item kuesioner variabel disiplin kerja diperoleh nilai signifikansi 2 tailed sebesar $0,000<0,05$, dengan demikian instrumen valid.

c. Dari hasil pengujian diperoleh seluruh item kuesioner variabel prestasi kerja diperoleh nilai signifikansi 2 tailed sebesar $0,000<0,05$, dengan demikian instrumen valid.

d. Dari hasil pengujian reliabilitas, diperoleh hasil sebagai berikut:

Tabel 1. Hasil Pengujian Reliabilitas

\begin{tabular}{|c|c|c|c|}
\hline Variabel & $\begin{array}{c}\text { Cronbach's } \\
\text { Alpha }\end{array}$ & $\begin{array}{c}\text { Standar Kritis } \\
\text { Alpha }\end{array}$ & Keterangan \\
\hline Pemberian Reward (X1) & 0,628 & 0,600 & Reliabel \\
\hline Disiplin Kerja (X2) & 0,633 & 0,600 & Reliabel \\
\hline Prestasi Kerja (Y) & 0,617 & 0,600 & Reliabel \\
\hline Kinerja Karyawan (Z) & 0,626 & 0,600 & Reliabel \\
\hline
\end{tabular}

Berdasarkan hasil pengujuan di atas, keseluruhan variabel Pemberian reward (X1), disiplin kerja (X2), prestasi kerja (Y) dan kinerja karyawan (Z) diperoleh nilai cronbach alpha lebih besar dari
0,600. Dengan demikian dinyatakan reliabel.

\section{Hasil Uji Asumsi Klasik} a. Uji Normalitas

Hasil uji normalitas dengan alat uji KolmogorovSmirnov Test, sebagai berikut:

Tabel 2. Hasil Normalitas Kolmogorov-Smirnov Test

Tests of Normality

Kolmogorov-Smirnova $\quad$ Shapiro-Wilk

\begin{tabular}{|c|c|c|c|c|c|c|}
\hline & \multicolumn{3}{|l|}{ Kolmoge } & \multicolumn{3}{|c|}{$0-v$} \\
\hline & Statistic & df & Sig. & Statistic & df & Sig. \\
\hline Prestasi Kerja (Y) & .077 & 96 & .190 & .973 & 96 & .047 \\
\hline
\end{tabular}

${ }^{*}$. This is a lower bound of the true significance.

a. Lilliefors Significance Correction

Berdasarkan hasil

pengujian pada tabel di atas diperoleh nilai signifikansi 0,190 dimana nilai tersebut 
lebih besar dari nilai $\alpha=0,050$ atau $(0,190>0,050)$. Dengan demikian maka asumsi distribusi persamaan pada uji ini adalah normal.

b. Uji Multikonilieritas
Uji multikolinearitas dilakukan dengan melihat nilai Tolerance Value dan Variance Inflation Factor (VIF). Adapun hasil pengujiannya sebagai berikut:

Tabel 3. Hasil Uji Multikolinieritas dengan Collinierity Statistic.

\begin{tabular}{|c|c|c|c|c|c|}
\hline \multirow[b]{2}{*}{ Model } & \multicolumn{2}{|c|}{$\begin{array}{l}\text { Coefficients } \\
\text { Unstandardized } \\
\text { Coefficients }\end{array}$} & \multirow{2}{*}{$\begin{array}{l}\text { Standardized } \\
\text { Coefficients } \\
\text { Beta }\end{array}$} & \multicolumn{2}{|c|}{$\begin{array}{c}\text { Collinearity } \\
\text { Statistics }\end{array}$} \\
\hline & $\mathrm{B}$ & Std. Error & & Tolerance & VIF \\
\hline 1 (Constant) & 9.041 & 3.081 & & & \\
\hline Pemberian Reward (X1) & .365 & .085 & .382 & .682 & 1.466 \\
\hline Disiplin Kerja (X2) & .417 & .088 & .421 & .682 & 1.466 \\
\hline
\end{tabular}

a. Dependent Variable: Prestasi Kerja $(\mathrm{Y})$

Berdasarkan hasil pengujian pada tabel di atas nilai tolerance masing-masing variabel bebas yaitu $0,682<1,0$ dan nilai Variance Inflation Factor (VIF) sebesar 1,466 < 10, dengan demikian model regresi ini tidak terjadi multikolinearitas.

\section{c. Uji Autokorelasi}

Pengujian dilakukan dengan alat uji Darbin-Watson (DW test). Adapun hasil pengujiannya sebagai berikut:

Tabel 4. Hasil Uji Autokorelasi

\section{Model Summary}

\begin{tabular}{ll|r|r|r|r} 
Model & $\mathrm{R}$ & $\mathrm{R}$ Square & $\begin{array}{c}\text { Adjusted } \mathrm{R} \\
\text { Square }\end{array}$ & $\begin{array}{c}\text { Std. Error of the } \\
\text { Estimate }\end{array}$ & Durbin-Watson \\
\hline 1 & $.710^{\mathrm{a}}$ & .504 & .493 & 2.465 & 1.947 \\
\hline
\end{tabular}

a. Predictors: (Constant), Disiplin Kerja (X2), Pemberian Reward (X1)

b. Dependent Variable: Prestasi Kerja (Y)

Hasil pengujian pada tabel di atas diperoleh nilai DurbinWatson sebesar 1,947 nilai tersebut berada diantara interval 1.550 - 2.460. Dengan demikian model regresi dinyatakan tidak ada gangguan autokorelasi.

\section{d. Uji Heteroskesdastisitas}

Pengujian dilakukan dengan alat uji Glejser Test Model. Adapun hasil pengujiannya sebagai berikut:

Tabel 5. Hasil Uji Heteroskesdastisitas dengan Glejser Test Model

\begin{tabular}{|c|c|c|c|c|c|}
\hline \multirow[b]{2}{*}{ Model } & $\begin{array}{r}\text { C } \\
\text { Unsta } \\
\text { Coe }\end{array}$ & $\begin{array}{l}\text { daricients } \\
\text { dardized } \\
\text { icients }\end{array}$ & \multirow{2}{*}{$\begin{array}{c}\text { Standardized } \\
\text { Coefficients } \\
\text { Beta }\end{array}$} & \multirow[b]{2}{*}{$t$} & \multirow[b]{2}{*}{ Sig. } \\
\hline & $\mathrm{B}$ & Std. Error & & & \\
\hline 1 (Constant) & 5.036 & 1.985 & & 2.537 & .013 \\
\hline Pemberian Reward (X1) & -.116 & .055 & -.260 & -2.125 & .036 \\
\hline Disiplin Kerja (X2) & .030 & .056 & .066 & .537 & .593 \\
\hline
\end{tabular}

a. Dependent Variable: RES2

Hasil pengujian dengan menggunakan uji glejser diperoleh nilai Sig. > 0,050. Dengan demikian regression model tidak ada gangguan heteroskesdastisitas. 


\section{Analisis Deskriptif}

Pada pengujian ini digunakan untuk mengetahui skor minimum dan maksimum skor tertinggi, ratting score dan standar deviasi dari masing-masing variabel. Adapun hasilnya sebagai berikut:

Tabel 6. Hasil Analisis Descriptive Statistics

\section{Descriptive Statistics}

\begin{tabular}{l|r|r|r|r|r} 
& N & Minimum & Maximum & Mean & Std. Deviation \\
\hline Pemberian Reward (X1) & 96 & 30 & 46 & 37.80 & 3.618 \\
\hline Disiplin Kerja (X2) & 96 & 31 & 45 & 38.45 & 3.497 \\
\hline Prestasi Kerja (Y) & 96 & 32 & 46 & 38.89 & 3.464 \\
\hline Kinerja Karyawan (Z) & 96 & 32 & 45 & 38.94 & 3.327 \\
\hline Valid N (listwise) & 96 & & & & \\
\hline
\end{tabular}

Pemberian reward diperoleh varians minimum sebesar 30 dan varians maximum 46 dengan ratting score sebesar 3,780 dengan standar deviasi 3,618.

Disiplin kerja diperoleh varians minimum sebesar 31 dan varians maximum 45 dengan ratting score sebesar 3,845 dengan standar deviasi 3,497.

Prestasi kerja diperoleh varians minimum sebesar 32 dan varians maximum 46 dengan ratting score sebesar 3,889 dengan standar deviasi 3,464

Kinerja karyawan diperoleh varians minimum sebesar 32 dan varians maximum 45 dengan ratting score sebesar 3,894 dengan standar deviasi 3,327.

\section{Analisis Kuantitatif}

Pada analisis ini dimaksudkan untuk mengetahui pengaruh variabel independen terhadap variabel dependen. Adapun hasil pengujian sebagai berikut:

\section{a. Analisis Regresi Linier Berganda}

Uji regresi ini dimaksudkan untuk mengetahui perubahan variabel dependen jika variabel independen mengalami perubahan. Adapun hasil pengujiannya sebagai berikut:

Tabel 7. Hasil Pengujian Regresi Linier Berganda

Coefficients $^{\mathrm{a}}$

Unstandardized

Coefficients

\begin{tabular}{|c|c|c|c|c|c|c|}
\hline \multirow{2}{*}{\multicolumn{2}{|c|}{ Model }} & \multicolumn{2}{|c|}{ Coefficients } & \multirow{2}{*}{$\begin{array}{c}\text { Coefficients } \\
\text { Beta }\end{array}$} & \multirow[b]{2}{*}{$\mathrm{t}$} & \multirow[b]{2}{*}{ Sig. } \\
\hline & & $B$ & Std. Error & & & \\
\hline 1 & (Constant) & 9.041 & 3.081 & & 2.934 & .004 \\
\hline & Pemberian Reward (X1) & .365 & .085 & .382 & 4.317 & .000 \\
\hline & Disiplin Kerja (X2) & 417 & .088 & .421 & 4.760 & .000 \\
\hline
\end{tabular}

a. Dependent Variable: Prestasi Kerja (Y)

Berdasarkan hasil pengujian pada tabel di atas, diperoleh persamaan regresi $\mathrm{Y}$ $=9,041+0,365 \mathrm{X} 1+0,417 \mathrm{X} 2$. Dari persamaan tersebut dijelaskan sebagai berikut:

1) Konstanta sebesar 9,041 diartikan jika Pemberian reward dan disiplin kerja tidak ada, maka telah terdapat nilai prestasi kerja sebesar 9,041 point.

2) Koefisien regresi Pemberian reward sebesar 0,365 , angka 
ini positif artinya setiap ada peningkatan Pemberian reward sebesar 0,365 point maka prestasi kerja juga akan mengalami peningkatan sebesar 0,365 point.

3) Koefisien regresi disiplin kerja sebesar 0,417, angka ini positif artinya setiap ada peningkatan disiplin kerja sebesar 0,417 point maka prestasi kerja juga akan mengalami peningkatan sebesar 0,417 point.

\section{b. Analisis}

\section{Determinasi}

Koefisien

Analisis

koefisien

determinasi dimaksudkan untuk mengetahui besarnya persentase pengaruh dari variabel independen terhadap variabel dependen baik secara parsial maupun simultan. Adapun hasil pengujian sebagai berikut:

Tabel 8. Hasil Pengujian

Koefisien Determinasi

Pemberian Reward Terhadap

Prestasi Kerja.

Model Summary

\begin{tabular}{lc|c|c|c} 
Model & $R$ & $\begin{array}{c}R \\
\text { Square }\end{array}$ & $\begin{array}{c}\text { Adjusted } \\
\text { S }\end{array}$ & $\begin{array}{c}\text { Std. } \\
\text { Error of } \\
\text { the }\end{array}$ \\
\hline 1 & $.619^{a}$ & .383 & .377 & 2.735 \\
\hline Estimate
\end{tabular}

$\begin{array}{cc}\text { Berdasarkan } & \text { hasil } \\ \text { pengujian diperoleh nilai }\end{array}$ determinasi sebesar 0,383 artinya Pemberian reward memiliki kontribusi pengaruh sebesar 38,3\% terhadap prestasi kerja.

Tabel 9. Hasil Pengujian

Koefisien Determinasi Disiplin Kerja Terhadap Prestasi Kerja.

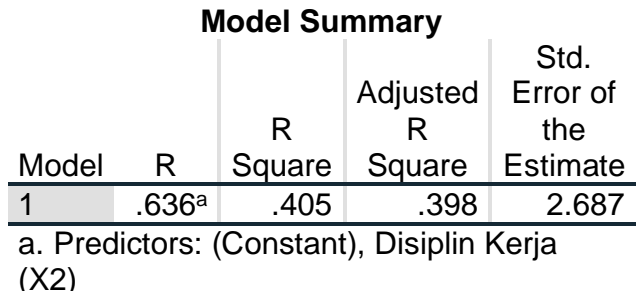

Berdasarkan hasil pengujian diperoleh nilai determinasi sebesar 0,405 artinya disiplin kerja memiliki kontribusi pengaruh sebesar 40,5\% terhadap prestasi kerja.

Tabel 10. Hasil Pengujian

Koefisien Determinasi

Pemberian Reward Dan

Disiplin Kerja Secara Simultan

Terhadap Prestasi Kerja.

Model Summary

\begin{tabular}{|c|c|c|c|c|}
\hline & & lodel Su & $\mathrm{mm}$ & \\
\hline odel & $\mathrm{R}$ & $\begin{array}{c}R \\
\text { Square }\end{array}$ & $\begin{array}{c}\text { Adjusted } \\
R \\
\text { Square }\end{array}$ & $\begin{array}{l}\text { Error of } \\
\text { the } \\
\text { Estimate }\end{array}$ \\
\hline & $.710^{a}$ & .504 & .493 & 2.465 \\
\hline
\end{tabular}

(X2), Pemberian Reward (X1)

Berdasarkan hasil

pengujian diperoleh nilai

determinasi sebesar 0,504

artinya Pemberian reward dan

disiplin kerja secera simultan memiliki kontribusi pengaruh sebesar 50,4\% terhadap prestasi kerja, sedangkan sisanya sebesar 49,6\% dipengaruhi faktor lain

Tabel 11. Hasil Pengujian Koefisien Determinasi Prestasi Kerja Terhadap Kinerja Karyawan. Model Summary

\begin{tabular}{|c|c|c|c|c|}
\hline \multicolumn{5}{|c|}{ Model Summary } \\
\hline Model & $\mathrm{R}$ & $\begin{array}{c}R \\
\text { Square }\end{array}$ & $\begin{array}{c}\text { Adjusted } \\
R \\
\text { Square }\end{array}$ & $\begin{array}{l}\text { Error of } \\
\text { the } \\
\text { Estimate }\end{array}$ \\
\hline 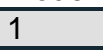 & $.620^{\mathrm{a}}$ & .384 & .377 & 2.625 \\
\hline \multicolumn{5}{|c|}{ a. Predictors: (Constant), Prestasi Kerja $(\mathrm{Y})$} \\
\hline & \multicolumn{3}{|c|}{ Berdasarkan } & hasil \\
\hline & leterm & & $\begin{array}{l}\text { diperoleh } \\
\text { sebesar }\end{array}$ & $\begin{array}{r}\text { nilai } \\
0,384\end{array}$ \\
\hline
\end{tabular}


artinya prestasi kerja memiliki

kontribusi pengaruh sebesar $38,4 \%$ terhadap kinerja karyawan.

c. Uji Hipotesis Uji hipotesis Parsial (Uji t)

Tabel 12. Hasil Uji Hipotesis Pemberian Reward Terhadap Prestasi Kerja. Coefficients $^{\mathrm{a}}$ Unstandardized Coefficients

\begin{tabular}{|c|c|c|c|c|c|}
\hline \multirow[b]{2}{*}{ Model } & \multicolumn{2}{|c|}{ Coefficients } & \multirow{2}{*}{$\begin{array}{c}\text { Coefficients } \\
\text { Beta }\end{array}$} & \multirow[b]{2}{*}{$\mathrm{t}$} & \multirow[b]{2}{*}{ Sig. } \\
\hline & $\mathrm{B}$ & Std. Error & & & \\
\hline $\begin{array}{ll}1 & \text { (Constant) }\end{array}$ & 16.481 & 2.945 & & 5.596 & .000 \\
\hline Pemberian Reward (X1) & .593 & .078 & .619 & 7.641 & .000 \\
\hline
\end{tabular}
a. Dependent Variable: Prestasi Kerja $(\mathrm{Y})$

Berdasarkan hasil pengujian pada tabel di atas, diperoleh nilai $\mathrm{t}$ hitung $>\mathrm{t}$ tabel atau $(7,641>1,984)$, dengan demikian hipotesis yang

Pengujian hipotesis dengan uji t digunakan untuk mengetahui hipotesis parsial mana yang diterima. Adapun hasil pengujian sebagai berikut: diajukan bahwa terdapat pengaruh yang signifikan antara Pemberian reward terhadap prestasi kerja diterima.

\begin{tabular}{|c|c|c|c|c|c|}
\hline \multirow[b]{2}{*}{ Model } & \multicolumn{2}{|c|}{$\begin{array}{l}\text { Coefficients }^{\mathbf{a}} \\
\text { Unstandardized } \\
\text { Coefficients }\end{array}$} & \multirow{2}{*}{$\begin{array}{l}\text { Standardized } \\
\text { Coefficients } \\
\text { Beta }\end{array}$} & \multirow[b]{2}{*}{$t$} & \multirow[b]{2}{*}{ Sig. } \\
\hline & B & Std. Error & & & \\
\hline $\begin{array}{ll}1 & \text { (Constant) }\end{array}$ & 14.662 & 3.043 & & 4.818 & .000 \\
\hline Disiplin kerja (X2) & .630 & .079 & .636 & 7.992 & .000 \\
\hline
\end{tabular}

a. Dependent Variable: Prestasi Kerja (Y)

Berdasarkan hasil pengujian pada tabel di atas, diperoleh nilai $\mathrm{t}$ hitung $>\mathrm{t}$ tabel atau $(7,992>1,984)$, dengan demikian hipotesis yang

Tabel 14. Hasil Uji Hipotesis Prestasi Kerja Terhadap Kinerja Karyawan.

\begin{tabular}{|c|c|c|c|c|c|}
\hline \multirow[b]{2}{*}{ Model } & \multicolumn{2}{|c|}{$\begin{array}{l}\text { Coefficients } \\
\text { Unstandardized } \\
\text { Coefficients }\end{array}$} & \multirow{2}{*}{$\begin{array}{l}\text { Standardized } \\
\text { Coefficients } \\
\text { Beta }\end{array}$} & \multirow[b]{2}{*}{$\mathrm{t}$} & \multirow[b]{2}{*}{ Sig. } \\
\hline & B & Std. Error & & & \\
\hline (Constant) & 15.795 & 3.036 & & 5.203 & .000 \\
\hline Prestasi Kerja $(\mathrm{Y})$ & .595 & .078 & .620 & 7.653 & .000 \\
\hline
\end{tabular}

a. Dependent Variable: Kinerja Karyawan (Z)

Berdasarkan hasil pengujian pada tabel di atas, diperoleh nilai $\mathrm{t}$ hitung $>\mathrm{t}$ tabel atau $(7,653>1,984)$, dengan demikian hipotesis yang diajukan bahwa terdapat pengaruh yang signifikan antara diajukan bahwa terdapat pengaruh yang signifikan antara disiplin kerja terhadap prestasi kerja diterima. 
Hipotesis ketiga: Terdapat pengaruh yang signifikan antara Pemberian reward, disiplin

Tabel 15. Hasil Uji Hipotesis Pemberian reward dan Disiplin kerja Secara Simultan Terhadap Prestasi Kerja.

\begin{tabular}{|c|c|c|c|c|c|c|}
\hline \multirow{2}{*}{\multicolumn{2}{|c|}{ Model }} & \multicolumn{3}{|c|}{ ANOVA $^{a}$} & \multirow[b]{2}{*}{$\mathrm{F}$} & \multirow[b]{2}{*}{ Sig. } \\
\hline & & Sum of Squares & $d f$ & Mean Square & & \\
\hline \multirow[t]{3}{*}{1} & Regression & 574.423 & 2 & 287.211 & 47.249 & $.000^{\mathrm{b}}$ \\
\hline & Residual & 565.317 & 93 & 6.079 & & \\
\hline & Total & 1139.740 & 95 & & & \\
\hline
\end{tabular}

a. Dependent Variable: Prestasi Kerja $(Y)$

b. Predictors: (Constant), Disiplin Kerja (X2), Pemberian Reward (X1)

Berdasarkan hasil pengujian pada tabel di atas, diperoleh nilai $\mathrm{F}$ hitung $>\mathrm{F}$ tabel atau (4,749>2,700), dengan demikian hipotesis keempat yang diajukan bahwa terdapat pengaruh yang signifikan antara Pemberian reward dan disiplin kerja secara simultan terhadap prestasi kerja diterima.

\section{PEMBAHASAN}

HASIL

\section{PENELITIAN}

\section{Pengaruh Pemberian Reward} Terhadap Prestasi Kerja

Pemberian reward berpengaruh signifikan terhadap prestasi kerja dengan nilai koefisien determinasi sebesar $38,3 \%$. Pengujian hipotesis diperoleh nilai $\mathrm{t}$ hitung $>\mathrm{t}$ tabel atau $(7,641>1,984)$. Dengan demikian hipotesis yang diajukan bahwa terdapat berpengaruh signifikan antara Pemberian reward terhadap prestasi kerja diterima.

\section{Pengaruh Disiplin Kerja Terhadap Prestasi Kerja}

Disiplin kerja berpengaruh signifikan terhadap prestasi kerja dengan nilai koefisien determinasi sebesar 40,5\%. Pengujian kerja dan motivasi terhadap prestasi kerja. 
t hitung > t tabel atau (7,653> 1,984). Dengan demikian hipotesis yang diajukan bahwa terdapat berpengaruh signifikan antara prestasi kerja terhadap kinerja karyawan diterima.

\section{KESIMPULAN DAN SARAN}

\section{Kesimpulan}

a. Pemberian reward berpengaruh signifikan terhadap prestasi kerja dengan kontribusi pengaruh sebesar $38,3 \%$. Uji hipotesis diperoleh nilai $\mathrm{t}$ hitung > t tabel atau (7,641 > 1,984).

b. Disiplin kerja berpengaruh signifikan terhadap prestasi kerja dengan kontribusi pengaruh sebesar 40,5\%. Uji hipotesis diperoleh nilai $\mathrm{t}$ hitung > $\mathrm{t}$ tabel atau $(7,992>$ 1,984).

c. Pemberian reward dan disiplin kerja secara simultan berpengaruh signifikan terhadap prestasi kerja dengan kontribusi pengaruh sebesar $50,4 \%$ sedangkan sisanya sebesar 49,6\% dipengaruhi faktor lain. Uji hipotesis diperoleh nilai $\mathrm{F}$ hitung $>\mathrm{F}$ tabel atau $(4,749>2,700)$.

d. Prestasi kerja berpengaruh signifikan terhadap kinerja karyawan dengan kontribusi pengaruh sebesar $38,4 \%$. Uji hipotesis diperoleh nilai $t$ hitung > t tabel atau (7,653 > $1,984)$.

\section{Saran}

a. Oleh karena reward berpengaruh positif dan signifikan terhadap prestasi kerja karyawan, maka disarankan kepada pihak manajemen agar lebih memperhatikan hal-hal yang menyangkut reward yang nantinya akan berdampak pada prestasi kerja karyawan.

b. Oleh karena disiplin kerja berpengaruh positif dan signifikan terhadap prestasi kerja karyawan, maka disarankan kepada pihak manajemen agar lebih memperhatikan hal-hal yang menyangkut disiplin kerja yang nantinya akan berdampak pada prestasi kerja karyawan.

c. Oleh karena pemberian reward dan disiplin kerja berpengaruh secara langsung terhadap prestasi kerja karyawan, untuk manajemen agar lebih memperhatikan hal-hal yang menyangkut reward dan disiplin kerja yang nantinya akan berdampak pada prestasi kerja serta kinerja karyawan.

\section{DAFTAR PUSTAKA}

Algifari. (2015). "Analisis Regresi untuk Bisnis dan Ekonomi". Yogyakarta: BPFE.

AM, E. N., et al. (2020). Pengaruh Pendidikan Dan Pelatihan Terhadap Kinerja Pegawai Direktorat Standarisasi Dan Pengendalian Mutu Kementerian

Perdagangan. Diklat Review: Jurnal manajemen pendidikan dan pelatihan, 4(3), 220-226.

Arikunto, Suharsimi (2014). "Prosedur Penelitian Suatu Pendekatan Praktek”. Bekasi: 
Rineka Cipta.

Damayanti, D., et al. (2021). Peran

Work Overload, Work

Environment, Work Family

Conflict \& Work Stress

Terhadap Job

Performance. Jurnal Ilmiah

Wahana Pendidikan, 7(3), 192206.

Edi Sutrisno (2016). Manajemen

Sumber Daya Manusia. Bekasi:

Prenadamedia Group.

Goklas, A., et al. (2021).

Management Of Organizational

Performance: The Role Of

Human Resource Management

Strategy. Jurnal

Ad'ministrare, 8(1), 245-254.

Hasibuan, Malayu S.P. (2016).

Manajemen Sumber Daya

Manusia. Edisi Revisi. Bekasi:

PT Bumi Aksara.

Imam Ghozali (2017). "Aplikasi Analisis Multivariate Dengan

Program SPSS”. Edisi Kelima.

Semarang: Badan Penerbit Undip.

Istijanto (2014) "Riset Sumber Daya

Manusia". Bekasi: PT.

Gramedia Pustaka

Kosasih, et al. (2021). Pengaruh

Lingkungan Kerja Dan Disiplin

Kerja Terhadap Produktivitas

Karyawan Pada PT. Graha

Curah Niaga Di Tangerang.

Jurnal Administrasi Bisnis

(JUBIS). 1(1). 1-10

Mangkunegara, Prabu Anwar. (2016).

Evaluasi Kinerja SDM.
Cetakan ke tujuh, PT Refika Aditama: Bandung.

Nurjaya, N., et al. (2021). Pengaruh

Kompetensi Sumber Daya

Manusia Dan Kemampuan

Pemanfaatan Teknologi

Terhadap Kinerja Aparatur

Desa Pada Kantor Kepala Desa

Di Kabupaten Gunungkidul, Yogyakarta. JENIUS (Jurnal

Ilmiah Manajemen Sumber

Daya Manusia), 4(3), 332-346.

Santoso, Singgih (2015). "Menguasai Statistik Multivariat”. Bekasi: PT Elex Media Komputindo.

Sedarmayanti. (2016). Sumber Daya Manusia dan Produktivitas Kerja. Bekasi: Mandar Maju.

Sudjana (2014) "Metode Statistika”, Bandung: Tarsido.

Sugiyono (2017), "Metode

Penelitian Administrasi : dilengkapi dengan Metode $R$ \& D”. Bandung: Alfabeta.

Veithzal Rivai (2015) Manajemen Sumber Daya Manusia Untuk Perusahaan, Bekasi: Raja Grafindo Persada.

Wibowo (2015) Manajemen Kinerja, Bekasi: PT. Raja Grafindo Persada.

Wicaksono, W., et al. (2021). Pengaruh Pelatihan, Motivasi Dan Budaya Organisasi Terhadap Kinerja Karyawan Pada PT Bank Mandiri, Tbk Di Jakarta. JENIUS (Jurnal Ilmiah Manajemen Sumber Daya Manusia), 5(1), 220-237. 